\title{
Abnormalities in liver function and coagulation profile following the Fontan procedure
}

\author{
R C van Nieuwenhuizen, M Peters, L J Lubbers, M D Trip, J G P Tijssen, B J M Mulder
}

Department of Cardiology, Academic Medical Centre, University of Amsterdam, Meibergdreef 9, 1105

AZ Amsterdam, Netherlands

R C van Nieuwenhuizen B J M Mulder M D Trip

\section{Department of Paediatric Haematology, Academic Medical Centre, University of Amsterdam M Peters}

Department of Paediatric Cardiology, Academic Medical Centre, University of Amsterdam L J Lubbers

Department of Clinical Epidemiology and Biostatistics, Academic Medical Centre, University of Amsterdam

J G P Tijssen

Correspondence to: Dr Mulder.

Accepted for publication 2 November 1998

\begin{abstract}
Objective-To investigate liver function and coagulation disorders in patients with a Fontan circulation at different time intervals after surgery.

Design-Retrospective analysis of clinical data and cross sectional study relating liver function and coagulation profile to time since surgery, in 28 surviving patients after the modified Fontan procedure.

Patients-20 patients (71\%) with atriopulmonary anastomosis, seven (25\%) with atrioventricular anastomosis, and one (4\%) with total cavopulmonary connection. Follow up ranged from 2.0 to 21.8 years (mean 11.1).

Results-Abnormal liver function tests, mainly reflecting cholestasis, were present in 21 patients who had a significantly longer follow up $(p<0.01)$. Protein synthesis was normal in almost all patients. Coagulation profile showed abnormalities in 22 patients. "Procoagulant" abnormalitiesthat is, decreased plasminogen and protein $C$ activity-were found in 11 and five patients, respectively. The extent of these abnormalities was less in patients with a longer follow up. Anticoagulant abnormalities were factor $V$ deficiency in 16 patients and factor VII deficiency in 17, resulting in a prolonged prothrombin time in 19 patients. Thirteen patients had both pro- and anticoagulant abnormalities. A prethrombotic state was present in five patients, with a significantly longer mean time interval since surgery $(p=0.05)$. Thus, although the individual procoagulant indices decreased with increasing time intervals since surgery, a prethrombotic state was found particularly in patients with a long term follow up.

Conclusions-Mild cholestasis was mainly present in Fontan patients with a long duration of follow up. Along with laboratory procoagulant abnormalities indicating a prethrombotic state, anticoagulant abnormalities were also present. The coagulation profile varied at different time intervals after surgery. Thus detailed evaluation should be performed regularly, and the use of anticoagulants should be considered in every patient. Long term prospective studies are needed to evaluate the individual fluctuations of coagulation profile over time following a Fontan procedure.

(Heart 1999;82:40-46)
\end{abstract}

Keywords: Fontan procedure; coagulation; liver function; congenital heart disease
Since 1971, the Fontan operation and its modifications have been used for definitive palliation in patients with tricuspid atresia and various forms of functionally univentricular hearts. ${ }^{12}$ One of the effects of the abnormal circulation is a chronically raised systemic venous pressure. ${ }^{3}$ This may cause abnormalities of liver size and function, such as coagulation disorders ${ }^{4}$ (protein C deficiency, ${ }^{5}$ factor VII deficiency ${ }^{6}$ ), liver fibrosis, ${ }^{7}$ hepatomegaly with or without ascites, ${ }^{8}$ and protein losing enteropathy. ${ }^{9}{ }^{10}$ As life expectancy is increasing in the Fontan population, ${ }^{11}$ these liver dysfunction and coagulation disorders are starting to cause clinical problems, for instance when patients require surgery. The abnormalities in coagulation profile that have previously been described in Fontan patients may predispose to thromboembolic events (for example, because of protein $\mathrm{C}$ and $\mathrm{S}$ deficiency), but also to prolonged bleeding (owing to factor $\mathrm{V}$ and factor VII deficiency). ${ }^{5}{ }^{6}$ Moreover, the enlarged right atrium may easily predispose to stasis and thrombus formation. ${ }^{12}$ Thus the coagulation profile in these patients is complex, and the use of anticoagulant treatment has been the subject of much discussion over the last few years. Not much is known about the variability in liver function disorders and coagulation profile abnormalities in relation to time since surgery or the duration of the Fontan circulation. The presence of coagulation factor abnormalities, which predispose to bleeding complications, has also only been investigated to a limited extent. The aim of this study was therefore to evaluate the severity of liver dysfunction and coagulation disorders in patients with a Fontan circulation, and to study the influence of time since surgery on the progress of these disorders.

\section{Methods}

PATIENTS

Of the 47 patients who had a Fontan operation performed in our institution between 1975 and 1995, 33 survived the initial operation. Five died of heart failure and the remaining 28 were included in our study. Patient characteristics and preceding palliative procedures are summarised in table 1 . The mean age of the patients was 18.0 years (range 6.4 to 36.4 ), and the mean interval after the first Fontan procedure was 11.1 years (2.0 to 21.8). The mean age at the first Fontan operation was 6.9 years (1.4 to 17.9).

At the time of the study, seven patients had undergone reoperation because of obstruction of the conduit. Table 2 shows the initial type of Fontan procedures and the number and type of reoperations. 
Table 1 Patient characteristics and previous palliative treatment $(n=28)$

\begin{tabular}{lr}
\hline Male & 18 \\
Female & 10 \\
Diagnosis & 15 \\
Univentricular heart & 13 \\
Tricuspid atresia & \\
Previous palliative procedures & 7 \\
None & 11 \\
Blalock-Taussig shunt & 3 \\
Glenn anastomosis & 3 \\
Waterston shunt & 2 \\
Blalock-Taussig shunt and Glenn anastomosis & $3^{\star}$ \\
Pulmonary trunk banding &
\end{tabular}

*One patient received a Glenn anastomosis after the pulmonary trunk banding.

All patients were seen at the outpatient clinic between 1995 and 1997. During this visit, blood was obtained for coagulation factors and liver function tests, and transthoracic echocardiography was performed to exclude intraatrial thrombi. Two patients receiving oral anticoagulants at the time of study for the treatment of thromboembolic complications were excluded from assessment of coagulation factors. In all patients, hepatitis (B or C) and vitamin $\mathrm{K}$ deficiency (assessed by the PIVKA test) were excluded.

The study was approved by the local medical ethics committee and informed consent was obtained from all patients or their parents.

\section{LABORATORY INVESTIGATIONS}

Variables included were those assumed appropriate for assessing liver function for synthesis, excretion, cholestasis, or hepatocellular damage. Serum concentrations of bilirubin (total and free), aspartate aminotransferase (AST), alanine aminotransferase (ALT), alkaline phosphatase, $\gamma$-glutamyltransferase $(\gamma \mathrm{GT})$, total protein, albumin, and pseudocholinesterase were measured with an automatic clinical analyser. Cholestasis was defined as an alkaline phosphatase value above the age related upper limit of normal range, a $\gamma \mathrm{GT}$ value $\geqslant 56$ $\mu \mathrm{mol} / \mathrm{l}$, a bilirubin (direct) value $\geqslant 7 \mu \mathrm{mol} / \mathrm{l}$, and/or a bilirubin (total) value $\geqslant 17 \mu \mathrm{mol} / 1$.

In addition, we assessed various abnormalities predisposing to thrombus formation (deficiency of plasminogen, antithrombin, and protein $\mathrm{C}$ and $\mathrm{S}$ ) and abnormalities predisposing to or reflecting an increased chance of bleeding (deficiency of factor V or VII (or both), prolonged prothrombin time, and activated partial prothrombin time (APTT)). We also measured the variables which, at increased levels, reflect a prethrombotic state (thrombin-antithrombin complex (TAT complex) and D-dimer).

For the coagulation study, venous blood samples were drawn in plastic syringes containing $3.2 \%$ trisodium citrate as anticoagulant in a ratio of nine parts of blood to one part of citrate. The blood sample was centrifuged $(12000 \times g(\times 10 \mathrm{~min}))$, plasma was collected and stored at $-70^{\circ} \mathrm{C}$ in $0.5 \mathrm{ml}$ aliquots. Blood was also collected in EDTA for platelet counting in a Coulter counter STKS or STKR. The APTT was determined by a one step method (Actin FS, DADE, Baxter, Florida, USA). The prothrombin time and coagulation factors $\mathrm{V}$ and VII were also determined by a one stage method (Thromboplastin IS, DADE). Antithrombin, protein $\mathrm{C}$ activity, and plasminogen were measured by a chromogenic assay (Coatest, Chromogenix, Mölndal, Sweden). D-dimers, products of the degradation of cross linked fibrin, were determined by enzyme linked immunoassay (ELISA; Diagnostica Stago, Asnières-sur-Seine, France). Total protein $S$, free protein $S$, proteins induced by vitamin $K$ absence (PIVKA), and the TAT complexes were determined by commercial ELISA methods (Boehringer Mannheim, Mannheim, Germany). Normal adult values are indicated in table 3. Values expressed as percentages refer to the percentage active in a normal plasma pool. Protein C activity levels achieve adult values around puberty and we therefore used normal values according to the age of the patient in all cases. ${ }^{13}$

\section{STATISTICAL ANALYSIS}

Linear regression analysis was used to determine the relation between laboratory variables and time since the first operation. Continuous variables were analysed by the paired Student's $t$ test. A p value $<0.05$ was considered statistically significant.

\section{Results}

LIVER FUNCTION

The results of the liver function tests are summarised in the upper panel of table 3. Twenty one of the 28 patients showed abnormalities in liver function tests. Of these, 18 showed signs of mild cholestasis. The most striking abnormality was increased $\gamma \mathrm{GT}$ in 13 patients. Sixteen patients had either increased alkaline phosphatase or $\gamma \mathrm{GT}$ levels, and in three patients both variables were increased. Five patients had increased levels of total and direct bilirubin. Compared with patients with a normal $\gamma \mathrm{GT}$, alkaline phosphatase, or bilirubin (direct and total), patients with signs of mild cholestasis were older (22.8 (7.2) v 9.5 (5.4) years (mean (SD); p < 0.01) and had a longer mean follow up interval (13.8 (5.1) v 6.3 (3.7) years, $\mathrm{p}<0.01)$. ALT was increased in nine patients, and AST was increased as well in two patients. Protein losing enteropathy, as a possible late complication after the Fontan procedure, ${ }^{910}$ was diagnosed in one of two patients with decreased plasma protein concentrations (albumin and total protein).

\section{Relation between liver function and time since first} operation

The relation between liver function variables and time since the first Fontan operation is shown in fig 1. Levels of $\gamma \mathrm{GT}$ and total bilirubin increased significantly with time since operation, as did levels of free bilirubin $(\mathrm{y}=0.21 \mathrm{x}+1.34, \mathrm{p}=0.05)$. AST and albumin showed no significant change with time after the first operation. The slight decrease in mean albumin concentration is caused by the two very low values. Levels of ALT, total protein, and pseudocholinesterase also showed no significant relation with time since surgery. 
Table 2 Type of Fontan procedure and reoperations $(n=28)$

\begin{tabular}{|c|c|c|c|}
\hline First operation & $\begin{array}{l}\text { Patients } \\
\text { (n) }\end{array}$ & $\begin{array}{l}\text { Reoperations } \\
(n)\end{array}$ & Type of reoperation (number) \\
\hline Right atrium-pulmonary artery & 20 & 2 & \\
\hline Hancock valved heterograft & 4 & 2 & $\begin{array}{l}\text { RA-PA direct anastomosis (1) } \\
\text { RA-PA aorta homograft (1) }\end{array}$ \\
\hline $\begin{array}{l}\text { Direct anastomosis } \\
\text { with atrial fenestration } \\
\text { without atrial fenestration }\end{array}$ & $\begin{array}{r}16 \\
8 \\
8\end{array}$ & 0 & \\
\hline Right atrium-right ventricle & 7 & 5 & \\
\hline Hancock valved heterograft & 5 & 3 & $\begin{array}{l}\text { RA-RV aorta homograft }(2) \\
\text { RA-RV non-valved heterograft }(1)\end{array}$ \\
\hline $\begin{array}{l}\text { Carpentier-Edwards valved } \\
\text { heterograft }\end{array}$ & 2 & 2 & $\begin{array}{l}\text { RA-RV pulmonalis homograft (1) } \\
\text { RA-RV non-valved heterograft (1) }\end{array}$ \\
\hline Total cavopulmonary connection & 1 & 0 & \\
\hline
\end{tabular}

PA, pulmonary artery; RA, right atrium; RV, right ventricle.

Alkaline phosphatase decreased physiologically over time $(\mathrm{y}=-11.70 \mathrm{x}+313.02, \mathrm{p}<0.01)$.

COAGULATION PROFILE

The results of the tests which reflect the coagulation profile are summarised in the lower panel of table 3 . In only two of the 24 patients evaluated were all the indices within the normal range. Thirteen of 20 patients had both procoagulant and anticoagulant abnormalities. Patients with signs of mild cholestasis did not have significantly more abnormalities of their coagulation profile than patients with no signs of cholestasis.

\section{Procoagulant abnormalities}

In 15 of the 24 patients evaluated, one or more coagulation abnormalities predisposing to thrombus formation (protein $\mathrm{C}$, protein $\mathrm{S}$, plasminogen, or antithrombin deficiency), or reflecting a prethrombotic state (increased D-dimer or TAT complex levels, or both), were present. Although albumin and total protein concentrations were decreased in only two patients, plasminogen values were decreased in 11 of 22 patients, while protein C activity was decreased in five of 21 patients. Of 19 patients evaluated, five were in a prethrombotic state. Clinical thrombotic events had occurred in two of these patients: thrombophlebitis in one and massive pulmonary thromboembolism in the other, causing death shortly after the laboratory investigation was done but before the results were available. In contrast, no clinical thrombotic events or intra-atrial thrombus formation occurred in the group of patients with normal TAT complex and D-dimer values. The mean time interval after the first operation was significantly longer in the patients who were in a prethrombotic state, at $15.8(5.0) v 10.1(5.7)$ years, $p=0.05)$. The mean age of this group of patients was not significantly different from that of the patients with normal TAT complex and $\mathrm{D}$-dimer values $(\mathrm{p}=0.07)$.

\section{Anticoagulant abnormalities}

Coagulation abnormalities reflecting an increased possibility of bleeding were found in 20 patients (factor V or factor VII deficiency, prolonged prothrombin time, prolonged APTT). The most striking abnormalities were a prolonged prothrombin time in 19 of 24 patients, and decreased levels of coagulation factors $\mathrm{V}$ and VII in 16 and 17 of 20 patients, respectively. All patients with a prolonged prothrombin time had decreased factor $\mathrm{V}$ or factor VII levels, or both. Both factor V and factor VII were decreased in 14 patients. Mean age and time after operation in these 14 patients were not significantly different from those in the other six patients. In two of the patients with anticoagulant abnormalities at the time of study, serious bleeding complications had occurred previously when they underwent laparoscopic cholecystectomy and surgery for a small umbilical hernia, respectively.

Table 3 Laboratory evaluation

\begin{tabular}{|c|c|c|c|c|c|}
\hline Variable & Normal value & $\begin{array}{l}\text { Investigated } \\
\text { patients }^{\star}(n)\end{array}$ & Mean (SD) & $\begin{array}{l}\text { Abnormal values } \\
(n(\%))\end{array}$ & $\begin{array}{l}\text { Abnormal values (mean } \\
\text { (range)) }\end{array}$ \\
\hline \multicolumn{6}{|l|}{ Liver function variables } \\
\hline Bilirubin direct $(\mu \mathrm{mol} / \mathrm{l})$ & $<7$ & 28 & $3.7(3.3)$ & $5(18)$ & $9.2(7.0$ to 12.0$)$ \\
\hline Bilirubin total $(\mu \mathrm{mol} / \mathrm{l})$ & $<17$ & 28 & $14.0(8.7)$ & $9(32)$ & $23.8(18.0$ to 39.0$)$ \\
\hline $\operatorname{ALT}(\mathrm{U} / \mathrm{l})$ & $<37$ & 28 & $31.8(9.9)$ & $9(32)$ & $42.9(37.0$ to 56.0$)$ \\
\hline AST (U/1) & $<47$ & 28 & $33.5(8.3)$ & $2(7)$ & $50.5(48.0$ to 53.0$)$ \\
\hline $\mathrm{AP}(\mathrm{U} / \mathrm{L})$ & Age related & 28 & $182.3(111.5)$ & $621)$ & Age related \\
\hline$\gamma \mathrm{GT}(\mathrm{U} / \mathrm{l})$ & $<56$ & 28 & $64.4(44.3)$ & $13(46)$ & 99.3 (60.0 to 218.0$)$ \\
\hline Protein $(\mathrm{g} / \mathrm{l})$ & 60 to 80 & 26 & $72.2(8.8)$ & $2(8)$ & 47.0 (42.0 to 52.0$)$ \\
\hline Albumin $(g / l)$ & $>35$ & 24 & $47.1(7.4)$ & $2(8)$ & $24.4(23.4$ to 25.4$)$ \\
\hline Pseudocholinesterase (U/l) & 3200 to 7500 & 23 & $5665(1540)$ & $1(4)$ & 2633 \\
\hline \multicolumn{6}{|l|}{ Haematological variables } \\
\hline Haemoglobin $(\mathrm{mmol} / \mathrm{l})$ & 7.5 to 10.0 & 28 & $9.2(1.0)$ & $7(25)$ & $10.6(10.0$ to 11.4$)$ \\
\hline Haematocrit $(1 / 1)$ & 0.37 to 0.45 & 25 & $0.43(0.05)$ & $6(24)$ & $0.50(0.47$ to 0.53$)$ \\
\hline Thrombocytes $\left(10^{9} / 1\right)$ & 150 to 350 & 27 & $205.5(57.3)$ & $3(11)$ & $119.3(101.0$ to 130.0$)$ \\
\hline \multicolumn{6}{|l|}{ Coagulation variables } \\
\hline $\mathrm{PT}(\mathrm{s})$ & 10.0 to 12.9 & 24 & $14.1(2.4)$ & $19(79)$ & $14.6(12.9$ to 23.1$)$ \\
\hline APTT (s) & 20 to 29 & 24 & $28.1(2.9)$ & $10(42)$ & $30.9(29.0$ to 34.0$)$ \\
\hline Factor V (\%) & 80 to 140 & 20 & $70.9(16.1)$ & $16(80)$ & $65.8(27.0$ to 79.0$)$ \\
\hline Factor VII $(\%)$ & 80 to 140 & 20 & $60.4(20.4)$ & $17(85)$ & $53.7(22.0$ to 75.0$)$ \\
\hline Antithrombin (\%) & 80 to 140 & 24 & $103.4(11.2)$ & $0(0)$ & - \\
\hline Plasminogen (\%) & 80 to 140 & 22 & $82.1(13.2)$ & $11(50)$ & $71.9(63.0$ to 79.0$)$ \\
\hline Protein C activity (\%) & Age related & 21 & $80.8(24.2)$ & $5(24)$ & Age related \\
\hline Protein S, total (\%) & 65 to 108 & 21 & $90.1(13.5)$ & $0(0)$ & - \\
\hline Protein S, free (\%) & 26 to 61 & 21 & $47.5(9.3)$ & $0(0)$ & - \\
\hline D-dimer $(\mu \mathrm{g} / 1)$ & $<400$ & 19 & $298(241)$ & $4(21)$ & 688.8 (412.0 to 990.0$)$ \\
\hline $\mathrm{TAT}(\mu \mathrm{g} / \mathrm{l})$ & $<4.6$ & 16 & $3.0(1.9)$ & $3(19)$ & $6.5(5.2$ to 7.2$)$ \\
\hline
\end{tabular}

^Not all measurements were available in for patients.

ALT, alanine aminotransferase; AP, alkaline phosphatase; APTT, activated partial thromboplastin time; AST, aspartate aminotransferase; $\gamma \mathrm{GT}$, $\gamma$-glutamyltranspeptidase; PT, partial thromboplastin time; TAT, thrombin-antithrombin complex. 

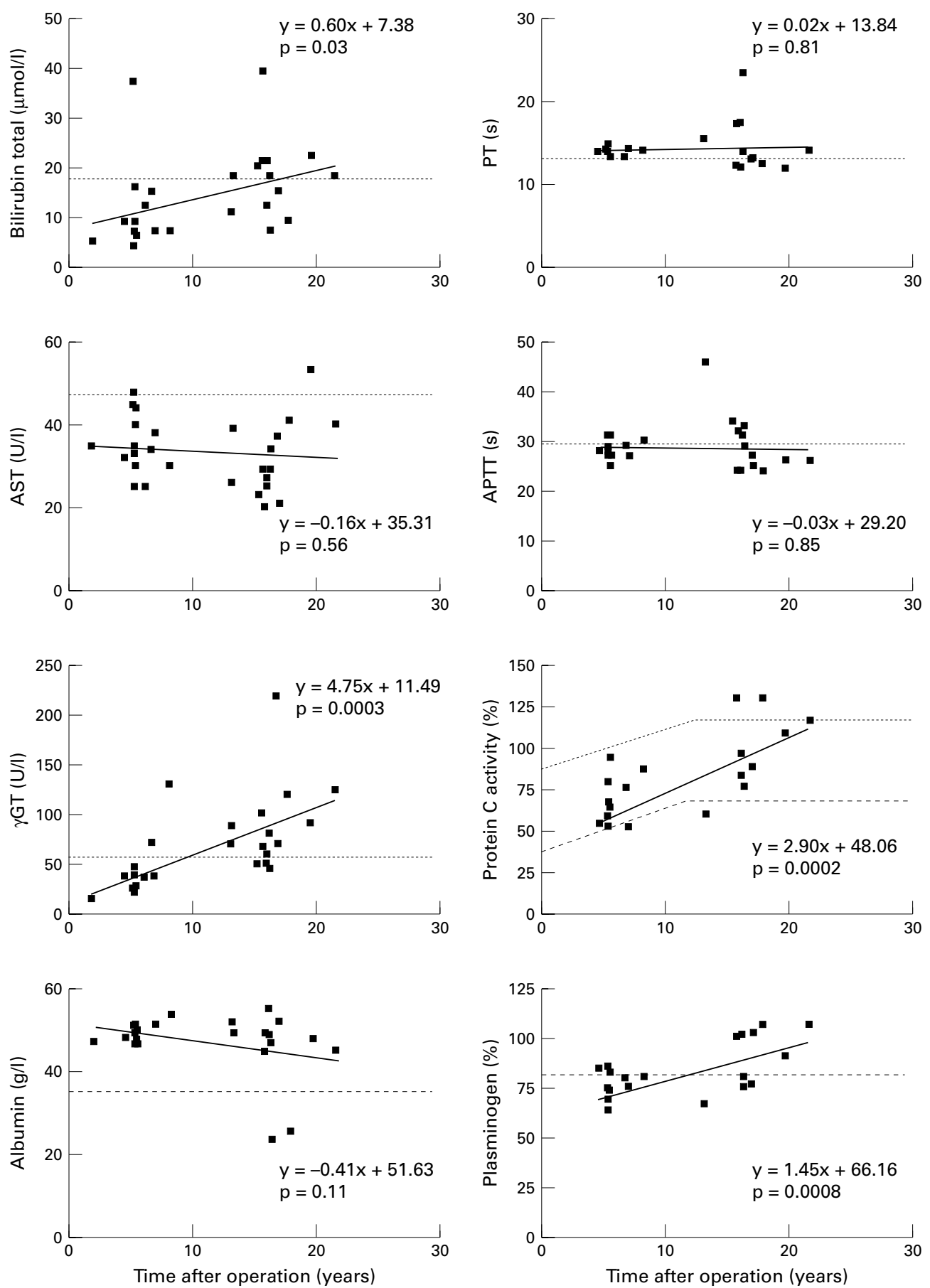

Figure 1 Relation between time since the first Fontan operation and different liver function variables. Solid line: linear correlation between the two variables; dotted line, upper limit of range of normal values; dashed line, lower limit of range of normal values. AST, aspartate aminotransferase; $\gamma G T, \gamma$-glutamyltranspeptidase.

Relation between coagulation profile and time since the first operation

The relation between coagulation variables and time since the first Fontan procedure is shown in fig 2. Coagulation factors which showed a significant increase with time after the first operation were: protein $\mathrm{C}$ activity, plasminogen, D-dimer $(y=20.00 x+83.49, p<0.05)$, and antithrombin $(\mathrm{y}=0.97 \mathrm{x}+91.87$, $\mathrm{p}=0.01)$. Neither prothrombin time and APTT, nor levels of factor V, factor VII, total

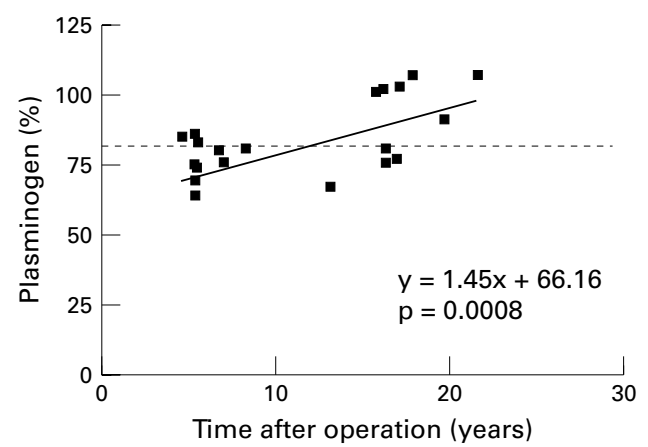

Figure 2 Relation between time since the first Fontan operation and different coagulation status variables. Solid line, linear correlation between the two variables; dotted line, upper limit of normal values; dashed line, lower limit of normal values. APTT, activated partial prothrombin time; PT, prothrombin time.

protein $\mathrm{S}$, free protein $\mathrm{S}$, and TAT complex showed any significant relation with time interval since surgery.

\section{Discussion}

Our results showed cholestatic liver function abnormalities in the majority of the patients, mainly in those with a long time interval (more than 10 years) since the first Fontan operation. However, the most striking findings were 
coagulation abnormalities, which could theoretically predispose to both thrombus formation and bleeding.

LIVER FUNCTION

Liver enzyme abnormalities and liver fibrosis have been reported after the Fontan procedure..$^{714}$ In our study, $75 \%$ of the patients had abnormalities of one or more liver function tests during a follow up period of two to 22 years. In $64 \%$ of the patients, these abnormalities mostly reflected signs of mild cholestasis without serious hepatocellular dysfunction. Similar findings have previously been reported by Kaulitz et al and Cromme-Dijkhuis et al one to nine years and one to 14 years after operation, respectively. ${ }^{5}$ In our study, patients with signs of mild cholestasis were significantly older and had a longer mean time interval since surgery than patients with no signs of cholestasis. These findings, combined with the significant linear increases in $\gamma \mathrm{GT}$ and bilirubin with time since surgery, suggest that the length of time after first surgery influences the extent of cholestasis. Neither Kaulitz et al nor CrommeDijkhuis et al, however, reported a significant relation between the liver function abnormalities and the various time intervals since surgery, but the length of follow up in their cross sectional studies was shorter. ${ }^{56}$

In our patients with a long time interval after surgery, outdated surgical techniques had been used, and these have now have been replaced mainly by total cavopulmonary connection. Therefore it is difficult to assess whether it is the length of time since surgery or the surgical technique which determines the extent of cholestasis.

In various studies, the synthesising function of the liver appeared to be normal, as plasma protein levels were generally within normal limits. ${ }^{6}{ }^{15}$ In our study, levels of albumin and total protein were also normal; however, plasma levels of coagulation factors, which also reflect the synthetic capacity of the liver, were severely decreased. As well as abnormalities in liver enzymes and liver function tests, liver fibrosis has also been reported as a sequel of the Fontan procedure, as a result of chronically increased systemic venous pressure. ${ }^{7}$ The clinical diagnosis of this condition is difficult and it is known that the correlation between the amount of fibrosis present and liver enzyme abnormalities or serum bilirubin levels is poor. ${ }^{1617}$ Thus, although the abnormalities in liver function seemed to be of limited severity in our study population, we could not assess the presence or severity of liver fibrosis. This of course can only be determined definitively by liver biopsy.

Coagulation factor abnormalities have been reported in patients with severe acute and chronic liver disease. ${ }^{18}$ Cromme-Dijkhuis et al suggested that, if the liver had a causal role in the origin of the observed deficiencies of coagulation factors in Fontan patients (such as protein $\mathrm{C}$ deficiency), there may be a selective disturbance of the synthesis function of the liver. ${ }^{6}$ In our study population, no relation was found between synthesis of coagulation factors and other proteins (albumin and total protein), which supports this suggestion. Also, no relations were found between other liver function disorders and coagulation factor abnormalities. This suggests that the degree of abnormality of liver function is of minor predictive value for the coagulation profile abnormalities.

\section{COAGULATION PROFILE}

Thromboembolism is a well known sequela of the Fontan procedure. ${ }^{12}{ }^{19-21}$ This complication may be partly caused by haemodynamic factors, such as chronically raised systemic venous pressure and flow stasis, but may also be due to coagulation abnormalities which predispose to thrombosis. ${ }^{4-6}$ Identified deficiencies of anticoagulant factors include inhibitors of protein $\mathrm{C}$ (which after activation is a potent inhibitor of factor $\mathrm{V}$ and factor VIII), protein S (cofactor of protein C), antithrombin (the main physiological inactivator of thrombin), and plasminogen (the proenzyme of the main fibrinolytic protease plasmin). In most studies, protein $\mathrm{C}$ deficiency has been the most pronounced coagulation profile abnormality following a Fontan procedure, the incidence varying from $25 \%$ to $75 \% .^{4}{ }^{512}$ In our study population, $24 \%$ of the patients had decreased levels of protein C. However, the most striking abnormality predisposing to thrombus formation in our study was plasminogen deficiency, present in $50 \%$ of the patients, though published reports cite incidences varying from $0 \%$ to $15 \% .^{45}{ }^{12}$ Both the protein $\mathrm{C}$ deficiency and the plasminogen and antithrombin deficiency decreased with time since surgery, theoretically suggesting a decreasing likelihood of thrombus formation with increasing time since the first Fontan procedure. A decrease in protein $\mathrm{C}$ deficiency in patients with a longer time interval since surgery was also found by Cromme-Dijkhuis et al. ${ }^{6}$

Increased levels of TAT complex (reflecting an increased amount of thrombin generated) and D-dimer (reflecting increased fibrinolysis) reflect hyperactive coagulation and thus a prethrombotic state. ${ }^{22-24}$ Two of five patients with a prethrombotic state developed thromboembolic events, compared with none in the group of patients with normal TAT complex and D-dimer values. Patients with a prethrombotic state had a significantly longer follow up than other patients (15.8 v 10.1 years, $p=0.05)$. This suggests an increased chance of thrombus formation in patients with a longer follow up, despite a decrease in the deficiencies of protein C, plasminogen, and antithrombin. Presumably haemodynamic influences which predispose to stasis and thrombus formation are the causal factors in this overall increased chance of thrombus formation with time since surgery.

In addition to the abnormalities predisposing to thrombus formation, we were interested in the abnormalities that predispose to bleeding. Two of the patients studied who underwent non-cardiac surgery developed prolonged bleeding after the operation. So far, no studies 
are available on this subject. Prothrombin time, which reflects synthesis of the coagulation factors of the extrinsic pathway (factor II, V, VII, $\mathrm{X}$, and fibrinogen) was prolonged in $79 \%$ of the patients, and APTT (reflecting the intrinsic pathway of coagulation) in $42 \%$ of the patients. In the two patients who suffered postoperative bleeding complications in the past, both prothrombin time and APTT were prolonged and TAT complex and D-dimer levels were within the normal range at the time of the study. The incidence of factor $\mathrm{V}$ and VII deficiency in our study was high compared with that in other studies, where factor V deficiency has been reported in $24 \%$ of the patients ${ }^{5}$ and factor VII deficiency in $43 \%{ }^{6}$

Because many patients had abnormalities of both procoagulant and anticoagulant pathways, no obvious predictions can be made, based on laboratory investigations, as to whether one individual patient is more likely to have thromboembolic complications than bleeding complications. Because of the high prevalence of thromboembolism after a Fontan procedure, ${ }^{12}{ }^{19-21}$ we assume that the imbalance between procoagulant and anticoagulant pathways, in combination with haemodynamic factors, causes a thrombotic tendency in the majority of the patients. The prevalence of bleeding complications, however, has not yet been thoroughly investigated. It is therefore unknown whether these complications specifically occur after a surgical procedure, as was the case with our two patients.

Recently, Bull emphasised that there is much uncertainty about prescribing anticoagulants to Fontan patients. ${ }^{25}$ Several investigators have suggested that all Fontan patients require long term anticoagulant treatment, ${ }^{12026}$ and this is now a standard procedure in many institutions in Fontan patients. Cromme-Dijkhuis et al suggested that patients with a low cardiac output or a dilated right atrium should be anticoagulated. ${ }^{6}$ Kaulitz et al recommended "vigorous anticoagulation treatment" in all Fontan patients with a procoagulant state. ${ }^{5}$ Bull, however, points out that prescribing oral anticoagulants may not be an optimal strategy because of the incidence of bleeding and the significant inconvenience to mostly young patients. ${ }^{25}$ In patients using long term anticoagulant treatment, annual rates of major and minor bleeding complications have been reported to range from $0.5 \%$ to $2.5 \%$ and from $6 \%$ to $16 \%$, respectively. ${ }^{27-29}$

We suggest that extensive laboratory investigation should be performed in every Fontan patient before anticoagulant treatment is initiated, because of the variation in coagulation profile in the individual patient. Prothrombin time and APTT (which reflect the risk of bleeding complications) and TAT complex and D-dimer (which reveal the presence of a prethrombotic state) should be included in this laboratory investigation. However, the decision on whether or not to start anticoagulant treatment in the individual patient should not be made only on the basis of the laboratory risk factors, but also on haemodynamic factors that suggest a compromised Fontan circulation.
Because some risk factors for thromboembolism show changes over time, clinicians should repeat these investigations during follow up.

\section{STUDY LIMITATIONS}

A relatively small number of patients was included in our study, with various types of Fontan procedure. Half of the patients had undergone an outdated type of Fontan procedure, which has now been replaced by the total cavopulmonary anastomosis and its modifications. We did not assess haemodynamic variables in detail, so the influence of haemodynamic data on abnormalities of coagulation factors and liver function could not be investigated. Another limitation is that laboratory investigations were performed only once in all patients without individual follow up, so no serial data were available.

CONCLUSIONS

Mild cholestasis and abnormalities of both the procoagulant and the anticoagulant pathways were found after a Fontan procedure. Detailed evaluation of coagulation profile should be performed regularly in every patient following a Fontan procedure, especially when anticoagulant treatment is being considered or when a surgical procedure is necessary. Long term prospective studies are needed to evaluate the individual fluctuations of coagulation profile and to evaluate the incidence of thromboembolic and bleeding complications after a Fontan procedure.

We gratefully thank Maarten Groenink for his useful assistance during the evaluation of the data.

1 Fontan F, Baudet E. Surgical repair of tricuspid atresia. Thorax 1971;26:240-8.

2 Fontan F, Kirklin JW, Fernandez G. Outcome after a "perfect" Fontan operation. Circulation 1990;81:1520-36.

3 Behrendt DM, Rosenthal A. Cardiovascular status after repair by Fontan procedure. Ann Thorac Surg 1980;29: repair by

4 Cromme-Dijkhuis AH, Henkens CMA, Bijleveld CMA, et al. Coagulation factor abnormalities as possible thrombotic al. Coagulation factor abnormalities as possible thrombotic
risk factors after Fontan operations. Lancet 1990;336: risk factors

5 Kaulitz R, Luhmer I, Bergmann F, et al. Sequelae after modified Fontan operation: postoperative haemodynamic data and organ function. Heart 1997;78:154-9.

6 Cromme-Dijkhuis AH, Hess J, Hählen K, et al. Specific equelae after Fontan operation at mid- and long-term follow-up. F Thorac Cardiovasc Surg 1993;106:1126-32.

7 Lemmer JH, Coran AG, Behrendt DM, et al. Liver fibrosis (cardiac cirrhosis) five years after modified Fontan operation for tricuspid atresia. F Thorac Cardiovasc Surg 1983;86:757-60.

8 Girod AD, Fontan F, Deville C, et al. Long-term results after the Fontan operation for tricuspid atresia. Circulation 1987;75:605-10.

9 Davis CA, Driscoll DJ, Perrault J, et al. Enteric protein loss after the Fontan operation. Mayo Clin Proc 1994;69:112-14.

10 Feldt RH, Driscoll DJ, Offord KP, et al. Protein-losing enteropathy after the Fontan Operation. $\mathcal{f}$ Thorac Cardioenteropathy after the Fontan
vasc Surg 1996;112:672-80.

11 Driscoll DJ, Offord KP, Feldt RH, et al. Five- to fifteen-year follow-up after Fontan operation. Circulation 1992;85:46996.

12 Jahangiri M, Ross DB, Redington AN, et al. Thromboembolism after the Fontan procedure and its modifications. Ann Thorac Surg 1994;58:1409-14.

13 Teunenbroek A van, Peters M, Sturk A, et al. Protein C activity and antigen levels in childhood. Eur f Pediatr 1990; 149:774-8.

14 Matsuda H, Covine E, Hirose H, et al. Acute liver dysfunction after modified Fontan operation for complex cardiac lesions. F Thorac Cardiovasc Surg 1988;96:219-26.

15 Jahangiri M, Shore D, Kakkar V, et al. Coagulation factor abnormalities after the Fontan procedure and its modificaabnormalities after the Fontan procedure and its
tions. F Thorac Cardiovasc Surg 1997;113:989-93.

16 Dunn GD, Hayes P, Breen KJ, et al. The liver in congestive heart failure (a review). Am ₹ Med Sci 1973;265:174-89.

17 Hirschmann JV. Pericardial constriction. Am Heart $f$ 1978;96:110-22. 
18 Vigano S, Mannucci PM, D'Angelo A, et al. The significance of protein $\mathrm{C}$ antigen in acute and chronic liver significance of protein C antigen in acute and ch
biliary disease. Am 7 Clin Pathol 1985;84:454-8.

19 Mair DM, Puga FJ, Danielson GK. Late functional status of survivors of the Fontan procedure performed during the 1970s. Circulation 1992;86 (suppl II):106-9.

20 Rosenthal DN, Friedman AH, Kleinman CS, et al. Thromboembolic complications after Fontan operations. Circulation 1995;92(suppl II):287-93.

21 Jonas RA. Intracardiac thrombus after the Fontan procedure [editorial]. F Thorac Cardiovasc Surg 1995;110:1502-3.

22 Hoek JA, Sturk A, ten Cate JW, et al. Laboratory and clinical evaluation of an assay of thrombin-antithrombin III complexes. Clin Chem 1988;34:2058-62.

23 Vukovich T, Teufelsbauer H, Fritzer M, et al. Hemostasis activation in patients with liver cirrhosis. Thromb Res 1995 77:271-7.

24 Tripodi A, Mannucci PM. Markers of activated coagulation and their usefulness in the clinical laboratory. Clin Chem 1996;42:664-9.
25 Bull K. The Fontan procedure: lessons from the past [editorial]. Heart 1998;79:213-14

26 Wilson DG, Wisheart JD, Stuart AG. Systemic thromboembolism leading to myocardial infarction and stroke after fenestrated total cavopulmonary connection. Br Heart $\mathcal{F}$ 1995;73:483-5

27 Connolly SJ, Laupacis A, Gent M, et al. Canadian atrial fibrillation anticoagulation (CAFA) study. $f$ Am Coll Cardiol 1991;18:349-55.

28 Singer DE, for the BAATAF Investigators. The effect of low-dose warfarin on the risk of stroke in patients with nonrheumatic atrial fibrillation. The Boston area anticoagulation trial for atrial fibrillation investigators. $\mathrm{N} \mathrm{Engl} \mathcal{F}$ Med 1990;323:1505-11.

29 Petersen P, Boysen G, Godtfredsen J, et al. Placebocontrolled, randomised trial of warfarin and aspirin for prevention of thromboembolic complications in chronic atrial fibrillation. The Copenhagen AFASAK study Lancet 1989;i:175-9. 